\title{
Relações entre ciclismo e rede de saúde e o caso de Curitiba
}

\author{
Relations between cycling and healthcare \\ network and the case of Curitiba
}

Hermes Eduardo Nichele [I]

\begin{abstract}
Resumo
Nesse momento da pandemia da Covid-19, quando surge a necessidade de distanciamento físico, a bicicleta afirma-se como modo alternativo vantajoso. Este artigo dispõe sobre a associação entre ciclismo e saúde através de um índice proposto para avaliar essa relação, o Índice de Mobilidade Cicloviária em relação à rede de Saúde (IMCS). A fundamentação teórica expõe as qualidades do modo cicloviário e as premissas que devem envolver seu planejamento. Como um estudo de caso, o sistema cicloviário de Curitiba e sua relação com as Unidades Básicas de Saúde são avaliados pelo IMCS, em seu estado atual e conforme o plano existente. Os resultados evidenciam que Curitiba negligencia a ciclomobilidade, com o sistema de saúde local praticamente inacessível pela malha cicloviária.
\end{abstract}

Palavras-chave: ciclismo; Covid-19; mobilidade sustentável; saúde; Curitiba.

\begin{abstract}
In the present moment of the COVID-19 pandemic, which demands social distancing, the bicycle confirms itself as an advantageous alternative mode. This article reflects on the association between cycling and health through an index proposed to evaluate such association, the Index of Cycling Mobility in relation to the Healthcare Network (in Portuguese, IMCS). The theoretical framework presents the qualities of cycling and the principles that the planning of bike lanes must involve. As a case study, Curitiba's cycling network and its relation to Primary Care Units are analyzed through the IMCS, in the current and projected situations. The results show that Curitiba neglects cycling mobility and that the local healthcare system is practically inaccessible through the cycling network.
\end{abstract}

Keywords: cycling; Covid-19; sustainable mobility; health; Curitiba. 


\section{Introdução}

O surto da doença do novo coronavírus que explodiu em 2020 trouxe mudanças inesperadas na rotina das cidades, ao mesmo tempo que expôs problemas de desigualdade no espaço urbano. A Organização Mundial da Saúde (OMS) declarou a enfermidade, chamada Covid-19, como pandemia mundial (OMS, 2020b) e recomendou o distanciamento social como uma forma de prevenção, a fim de diminuir a disseminação do vírus enquanto vacinas e outras formas efetivas de tratamento não eram aprovadas (OMS, 2020a).

0 distanciamento social mudou a rotina da população e, consequentemente, o cenário das cidades e da mobilidade urbana. As precariedades do transporte público e os problemas dos modos motorizados individuais são escancarados explicitamente. Os modos ativos, o andar a pé e a bicicleta, aparecem com maior força na pandemia, dada a necessidade do afastamento físico e da manutenção de exercícios físicos (Park, Kim e Lee, 2020; Teixeira e Lopes, 2020). A bicicleta precisa de um sistema cicloviário organizado, para pleno funcionamento como modo de transporte, e a qualidade dessa malha depende não só da sua extensão, mas também de aspectos como a associação com destinos usuais no meio urbano, como é o caso da rede de saúde.

Assim, este artigo pretende analisar o sistema cicloviário de uma cidade em relação à sua rede de saúde através de um índice próprio, o Índice de Mobilidade Cicloviária em relação à rede de Saúde (IMCS). 0 estudo de caso utilizado é o município de Curitiba, no seu cenário atual e no projetado pelo recente Plano de Estrutura Cicloviária. A fim de embasar essa análise, o texto busca compreender as vantagens de saúde física e mental que o modo cicloviário, a bicicleta, proporciona e como pode ser significativo nos tempos da pandemia e no porvir do pós-coronavírus.

O trabalho está dividido em seis seções: esta seção de (1) "Introdução" apresenta o tema e o objetivo do artigo; em (2) "Distanciamento social, mobilidade urbana e a bicicleta", são colocadas as fundamentações teóricas acerca do contexto da Covid-19 e das vantagens da bicicleta para a mobilidade sustentável, além da conceituação de sistema cicloviário e do que ele necessita; a seção (3) "Procedimentos metodológicos" trata da trilha científica do trabalho; na seção (4) "O sistema cicloviário de Curitiba", são apresentadas a situação da malha cicloviária curitibana atual e a avaliação geral do plano de 2019; na seção (5) "Resultados e discussão", o IMCS é calculado e os valores são analisados criticamente; por fim, a seção (6) "Considerações finais" traz comentários conclusivos e de rumo a futuras pesquisas.

\section{Distanciamento social, mobilidade urbana e a bicicleta}

A doença Covid-19, diagnosticada ainda no fim de 2019, começou a se espalhar rapidamente pelo mundo e foi declarada como uma pandemia pela OMS, em março de 2020. A rápida dispersão e a gravidade da doença são um cenário inédito para um mundo globalizado e tão conectado. No Brasil, um dos países mais afetados, a incidência de Covid-19 aumentou, de outubro de 2020 para abril de 
2021, de aproximadamente 2.290 para 6.028 novos casos a cada cem mil habitantes, com a taxa de mortalidade crescendo mais que o dobro nesse intervalo (Dong, Du e Gardner, 2020). E, uma vez que a vacinação tem avançado lentamente, a medida recomendada pela OMS para a prevenção desde o início do surto foi a de distanciamento social. 0 afastamento físico de pessoas é a forma mais simples de evitar o contágio e a disseminação do novo coronavírus. Assim, vários países instituíram restrições para evitar aglomerações, o chamado lockdown. Foi necessária a diminuição das atividades de produção, comércio e serviços nesse período de lockdown, para garantir o distanciamento social, algo que trouxe impactos na mobilidade urbana dos grandes centros urbanos ao redor do mundo. A habitual lotação do transporte público é posta em xeque nesse momento em que é preciso as pessoas ficarem afastadas umas das outras (Teixeira e Lopes, 2020). 0 mesmo acontece com o transporte motorizado individual, cujo espaço disponível nas vias aumentou na quarentena, dada a redução do tráfego. Katrakazas et al. (2020) discutem as mudanças de comportamento do trânsito em cidades da Grécia e da Arábia Saudita durante o lockdown: aumento da velocidade, de frenagens bruscas e menor tempo de deslocamento.

Porém, os automóveis e motocicletas, que representam a modalidade motorizada individual, carregam problemas de poluição e de maiores gastos. Além disso, em tempos normais, o trânsito repleto de veículos particulares provoca congestionamentos e mais acidentes (Alves e Cunha, 2017; Miranda e Vieira, 2019).

No Brasil, a mobilidade urbana das cidades é dominada pelos automóveis. Netto e Ramos (2017) destacam que a política rodoviarista iniciada no período de expansão da urbanização, a partir de meados do século $\mathrm{XX}$, criou um cenário que privilegia os modos de transporte individuais. Os interesses da indústria automobilística e do mercado imobiliário geraram cidades espraiadas, dependentes de um sistema viário que conectasse os lugares da maneira mais eficiente possível. Como o transporte público não recebeu os investimentos necessários para cobrir essa demanda de movimentação, os carros e as motocicletas tornaram-se soberanos do espaço público das vias, contribuindo para a segregação urbana e as inequidades do direito à cidade, conforme escrevem Carvalho e Britto (2016). O fenômeno de periferização das cidades está, portanto, intimamente ligado às condições de mobilidade urbana. A segregação e a expulsão das classes menos favorecidas para as periferias urbanas longínquas, juntamente com sistemas de transporte público precários, propiciam a ampliação da frota de veículos individuais (Alves e Cunha, 2017; Vasconcellos, 2013).

Assim, o Brasil chegou na pandemia da Covid-19 com os centros urbanos subordinados aos automóveis e com sistemas de transporte público inaptos e deficientes. As medidas necessárias para estabelecer um lockdown completo foram fragmentadas de estado para estado e de cidade para cidade, em meio à crise política. Quando instalada, em abril de 2020, a quarentena não teve a duração e as restrições intensas o suficiente para frear 0 avanço do novo coronavírus, e a movimentação das cidades continuou ocorrendo. 0 trajeto casa-trabalho não paralisou e, para piorar, a frota dos coletivos foi reduzida na tentativa do poder público de restringir a movimentação. Na zona Leste de São Paulo, por exemplo, a oferta de ônibus reduziu $61,6 \%$, com a 
demanda caindo $63,6 \%$ nesse período mais restritivo. Na região central da capital paulista, as linhas circulando diminuíram $61,3 \%$, com a demanda decaindo 68\% (Giannotti, 2020). Esses números mostram como a quantidade de passageiros manteve-se párea com a disponibilidade do transporte, com a área periférica tendo menor redução do que a zona central. Além disso, a partir de maio já surgiram deliberações de reabertura de comércio e serviços. A partir de então, a situação variou num efeito sanfona entre fechamentos brandos e reaberturas nos meses subsequentes. Ocorre um desalinhamento entre a demanda e a capacidade dos ônibus e metrôs, com a impossibilidade de as pessoas seguirem o distanciamento social, agravando os riscos de contágio pelo contato físico (ibid.).

Essa conjuntura faz com que a importância e a validade do transporte público sejam questionadas. Aloi et al. (2020) discutem essa problemática, indicando que as cidades devem procurar alternativas para evidenciar a qualidade e a praticabilidade dos modos coletivos. E um componente complementar aos ônibus, metrôs, trens, VLTs e demais modos que formam o rol do transporte público pode ser a bicicleta.

A bicicleta é notabilizada e realçada como uma alternativa eficaz na mobilidade urbana, em meio a essa conjuntura caótica que se deflagrou em 2020. Primeiramente, em relação aos aspectos de distanciamento social, requisitados para evitar o contágio da Covid-19, o modo cicloviário é bastante eficaz, pois a pedalada naturalmente exige afastamento entre as pessoas (Park, Kim e Lee, 2020; Teixeira e Lopes, 2020).
Além disso, a bicicleta age como atividade física, algo que é defasado pelo isolamento das pessoas em suas casas. A OMS aconselha pelo menos 150 minutos de exercício físico moderado por semana, ou 75 minutos de exercício mais intenso, prática que Hammami et al. (2020) descrevem como possíveis de serem realizadas no ambiente da casa. Porém, no Brasil, isso não é uma realidade factível para todos, dados os altos níveis de precariedade de moradias, também explicitados durante o surto do novo coronavírus (Ramalhoso, 2020). Da mesma forma, é importante sublinhar que o isolamento social preconizado durante a pandemia pode ser gatilho para o surgimento ou agravamento de enfermidades mentais, conforme escrevem Borloti et al. (2020). À vista disso, a bicicleta aparece como uma opção exequível tanto para a manutenção de atividades físicas, por ser propriamente um exercício, quanto para o alívio mental do isolamento, uma vez que a pedalada também contribui para a saúde mental (Park, Kim e Lee, 2020), tendo ainda um baixo custo de aquisição e de manutenção (Miranda e Vieira, 2019).

Algumas cidades ao redor do mundo já registraram aumento do número de pessoas pedalando durante a quarentena. Park, Kim e Lee (ibid.) apresentam dados de crescimento da utilização do sistema de compartilhamento de bicicletas de Seul, enquanto Teixeira e Lopes (2020) descrevem esse incremento ocorrendo no Citi Bike, o programa de compartilhamento cicloviário de Nova York.

E essas são as vantagens imediatas em relação à doença Covid-19. Porém, mais do que uma opção para o distanciamento social e a manutenção da prática de exercícios durante 
a pandemia, o ciclismo pode ser estendido também para a rotina das viagens pendulares dos espaços urbanos. Ou seja, a bicicleta pode funcionar como um modo utilitário e predominante nos deslocamentos do dia a dia das cidades. Esse ideal já é, há algum tempo, discutido como uma alternativa viável e recomendável na busca da mobilidade urbana sustentável (Carvalho e Freitas, 2012; Alves e Cunha, 2017). Afinal, é uma modalidade que reúne diversos benefícios: exige menos espaço nas vias, possui flexibilidade na composição das rotas, demanda menos custos de manutenção da sua infraestrutura, não polui o meio ambiente e, como já dito, traz benefícios para a saúde física e mental, além de baixos custos de compra e de manutenção para o usuário (Nakamori et al., 2015; Miranda e Vieira, 2019).

É reconhecível o avanço que algumas cidades europeias tiveram no incentivo ao ciclismo utilitário nas duas últimas décadas, na implantação de estruturas para tal modo de transporte, com consequente aumento do número de ciclistas e diminuição da frota de veículos. Copenhague, a capital da Dinamarca, é o caso mais notável (Carvalho e Freitas, 2012; Carvalho e Brito, 2016). No Brasil, a legislação nacional coloca os modos ativos como prioritários no trânsito e na construção de políticas de mobilidade, ao menos na teoria. 0 Código de Trânsito Brasileiro (CTB) (Brasil, 1997) dispõe que a bicicleta tem preferência sobre os veículos automotores na circulação das vias, quando não há infraestrutura própria.

A Política Nacional de Mobilidade Urbana (PNMU) (Brasil, 2012) é a lei criada para fundamentar as políticas de planejamento urbano de forma que proporcionem a plena acessibilidade de pessoas e cargas nas cidades.
Nas suas diretrizes, é prescrita a prioridade do transporte não motorizado sobre os demais, na busca da mobilidade urbana sustentável.

Assim, é relevante, para a base teórica deste trabalho, uma explanação breve sobre o termo mobilidade urbana sustentável. Ao longo do século XX, o tema da mobilidade era abordado de maneira essencialmente técnica, voltando-se a soluções de engenharia de tráfego. A problemática de movimentação era vista como um transtorno de capacidade de atendimento a uma demanda de trânsito. Atualmente, o assunto adquiriu uma denotação mais qualitativa, orientando-se pelo impacto socioambiental dos sistemas de transporte, pelos desafios da transição ecológica que afeta as matrizes energéticas dos países e pelos limites da conjuntura sociocultural dos habitantes de grandes cidades (Araújo-Lima e Tapie, 2018).

Essas considerações permitem compreender o conceito de mobilidade urbana sustentável como aquela que abrange as necessidades sociofuncionais de deslocamento na atualidade, mas também contribui para a preservação do ambiente e das condições para as gerações futuras (Carvalho, 2016). Para esse objetivo, diversas modalidades são acolhidas como prioritárias: deslocamento a pé, bicicleta, patinete, skate - os modos não motorizados - e os diferentes modos motorizados públicos, como ônibus, tramways, metrôs, trens urbanos, balsas, etc. Essas modalidades coletivas devem ter baixo impacto quanto a emissões atmosféricas, devem ser fundamentais em combustíveis renováveis e precisam garantir condições de eficiência e conforto para a população. É essencial também a implantação integrada à malha urbana através de mecanismos de desenho urbano 
que almejem funcionalidade e segurança universais (Del Rio, 1990). Assim, o transporte ativo (pedonal e cicloviário) aparece como foco que políticas de desenvolvimento urbano e de transportes devem ter, a fim de ser almejada a mobilidade sustentável.

Porém, a cultura de ode ao carro coloca a bicicleta e os pedestres como secundários nas ruas e no planejamento urbano, ocasionando-lhes situações de risco nos seus trajetos. Desse modo, os marcos regulatórios, como o CTB e a PNMU, não serão suficientes enquanto o poder público não agir efetivamente em prol da mobilidade urbana sustentável e do desestímulo da priorização dos automóveis (CarvaIho e Brito, 2016).

Na utilização da bicicleta, as pessoas enfrentam diversas barreiras nos trajetos. As principais estão relacionadas com a falta de infraestrutura, como ciclovias, ciclofaixas e paraciclos. Não havendo essa malha cicloviária, os usuários acabam pedalando junto aos veículos motorizados, encarando a agressividade dos condutores e a falta de espaço na via (Battiston, Olekszechen e Debatin Neto, 2017; Miranda e Vieira, 2019).

Ainda que haja esses impedimentos e outros mais, como condições topográficas, climáticas e a própria percepção cultural negativa sobre a bicicleta (Battiston, Olekszechen e Debatin Neto, 2017), a quantidade de ciclistas nas cidades tem aumentado nos últimos vinte anos, bem como as pesquisas e os estudos do assunto. Carvalho e Freitas (2012), em um texto de revisão, mostram como os trabalhos acerca do tema ciclismo e saúde começaram a se intensificar a partir de 2003. Nakamori et al. (2015) descrevem a importância do apoio da comunidade acadêmica para a discussão da relevância e das potencialidades do modo cicloviário. Já Abílio e Vasconcellos (2017) discutem a crescente ocupação do espaço viário de São Paulo pelos ciclistas ao longo da década de 2010.

Portanto, a bicicleta tem deixado de ser vista como um modo de transporte de lazer, de uso esporádico e de concepção cultural de desprezo. Fica claro o valor do ciclismo utilitário, aquele em que o indivíduo pedala para atingir atividades de trabalho, estudo, compras, serviços, etc. (Sousa e Penha-Sanches, 2019; Miranda e Vieira, 2019).

É importante ainda ressaltar o recente aumento do uso da bicicleta como meio direto de trabalho, com a ascensão das plataformas digitais de entrega. Por meio de parcerias assimétricas, entre o aplicativo e as entregadoras e entregadores ciclistas, estes se submetem a longas jornadas de trabalho, em meio a insegurança e violência das ruas. 0 pagamento é ínfimo e não há nenhuma garantia de direitos trabalhistas, o que leva o ciclista a várias horas de expediente, provocando fadiga e exposição contínua aos perigos do trânsito. São as condições chamadas de uberização do trabalho, semelhantes às de motoristas de aplicativo, mas aplicadas aos ciclistas que recorrem a esse tipo de atividade às vezes como única renda. Durante a pandemia da Covid-19, houve um aumento das entregas, já que se intensificaram os pedidos em domicílio. Porém, esse acréscimo não foi refletido em melhores pagamentos e condições. Aos entregadores não restou outra opção senão sair nas ruas para trabalhar em contato com outras pessoas, enquanto as medidas de distanciamento aconselhavam o contrário. Assim, a categoria, que une tanto ciclistas quanto motociclistas, reuniu-se no movimento "Breque dos Apps", organizando uma paralisação no dia 1 ㅇ de julho de 2020 (Peres, 2020). 
Todos esses aspectos discutidos revelam os problemas enfrentados por ciclistas no Brasil, desde a imagem negativa da cultura que exalta o carro até as condições péssimas de trabalho que envolvem os entregadores de aplicativos, passando ainda pela negligência das políticas públicas em dar prioridade ao modo e pela falta de infraestrutura de qualidade para a bicicleta.

A partir disso, é relevante compreender como as malhas cicloviárias deveriam ser projetadas e implantadas, considerando o contexto nacional. Para que as pessoas adeptas ao ciclismo, tanto ao utilitário quanto ao de lazer, possam pedalar com segurança e eficiência nas cidades, são necessárias a criação e a manutenção de um sistema cicloviário nas cidades. O sistema é composto pela infraestrutura pelos apoios à bicicleta. A infraestrutura é formada pelas vias cicláveis, que envolvem pavimentação e sinalização, e são em geral divididas nas seguintes categorias, conforme Tischer (2017) e Cardoso e Campos (2014):

a) Ciclovia: espaço dedicado exclusivamente ao ciclista, segregado fisicamente do passeio e da pista de rolamento, com vantagem da segurança para o usuário;

b) Ciclofaixa: faixa contida na calçada ou na pista de rolamento, que acompanha a malha viária, mas sem a separação física;

c) Espaço compartilhado: definição da divisão do espaço com outro modo, seja na calçada ou na pista de rolamento, onde a bicicleta tem preferência para trafegar, considerando a segurança do pedestre no caso dos passeios;

d) Ciclorrota: criação de um caminho esquemático e prático para o ciclista sobre as faixas de rolamento das vias, geralmente vias locais de baixo tráfego, com a preferência do ciclista, conforme o CTB.
As vias cicláveis podem ser caracterizadas por ser de sentido único ou duplo, conforme largura suficiente e/ou existência de sentido contrário correspondente. Os apoios ao modo envolvem estacionamentos próprios (paraciclos), bicicletários, duchas e mecanismos de integração com o transporte público (Nakamori et al., 2015; Vale, 2016).

Para a concepção e a implementação de um eficiente e adequado sistema cicloviário, algumas pesquisas e manuais foram desenvolvidos, bem como métodos de avaliação de sistemas existentes. O Manual de Planejamento Cicloviário é uma publicação feita pela extinta Empresa Brasileira de Planejamento de Transportes (Geipot, 2001) que compila recomendações sobre a criação de uma rede cicloviária e sobre aspectos projetuais da malha cicloviária. Em 2007, a Secretaria Nacional de Transporte e da Mobilidade Urbana, do extinto Ministério das Cidades, publicou o Caderno de Referência para elaboração de Plano de Mobilidade por Bicicleta nas Cidades (Bicicleta Brasil, 2007). Trata-se de uma cartilha destinada ao tema que, inclusive, resgata indicações do manual da Geipot. Já, em 2017, o Instituto de Políticas de Transporte e Desenvolvimento (ITDP) lançou o Guia de Planejamento Cicloinclusivo, que enfatizava a importância da ciclomobilidade em seus aspectos gerais e dava diretrizes para projetar estruturas próprias à bicicleta.

Cardoso e Campos (2014) procuram estabelecer uma metodologia para planejar um sistema cicloviário, considerando os documentos da Geipot e da Bicicleta Brasil. Através de uma revisão bibliográfica e de pesquisas com ciclistas do Rio de Janeiro, os autores estabeleceram cinco etapas que o planejamento de infraestrutura ciclável deveria levar em conta: 
Etapa 1 - Definição da área de abrangência: a identificação do sistema viário deve vir acompanhada da pontuação dos polos geradores de viagens (PGVs), que são os empreendimentos capazes de atuarem como destino de elevado número de viagens;

Etapa 2 - Identificação de caminhos mínimos: através de uma rede de conexões viárias entre os PGVs, são estabelecidos os trajetos considerados mais eficientes nessa etapa. Vale (2016) destaca como as viagens de até 5 quilômetros são as que a bicicleta pode agir como mais eficiente modo. A cobertura de distâncias similares pela bicicleta é indicada também por Nakamori et al. (2015);

Etapa 3 - Medição da qualificação das vias nesses caminhos previamente identificados: Cardoso e Campos sugerem cálculos de cinco indicadores: largura efetiva da via; presença de estacionamentos para automóveis; limite de velocidade; volume de tráfego; presença e caracterização de aclives;

Etapa 4 - Proposição de mudanças em trechos considerados inadequados, a partir da qualificação pronta, seja por escolha de vias próximas ou por investimentos e alterações no sistema viário existente;

Etapa 5 - Análise e sugestão de melhorias no sistema cicloviário como um todo.

Em todas essas etapas, deve ser considerada a participação popular no processo, com possibilidade de fiscalizar e avaliar o andamento, conforme a PNMU (Brasil, 2012). A disposição dessas premissas para a criação de um sistema cicloviário se justifica pela análise crítica que será feita mais adiante sobre a situação existente da malha cicloviária de Curitiba e o Plano de Estrutura Cicloviária, projetado e aprovado em 2019 (Curitiba, 2019). Além disso, essa listagem de passos mostra como é simples e pouco dispendiosa a instalação de um sistema próprio para a bicicleta, conforme comentam Miranda e Vieira (2019).

\section{Procedimentos metodológicos}

Com esse arcabouço teórico e crítico como base, esta seção apresenta os procedimentos metodológicos para a análise do sistema cicloviário de Curitiba (existente e proposto), sob a ótica de eficiência e em associação com aspectos de saúde. Por se tratar de uma questão investigativa, a fim de se compreender um processo no seu todo, Yin (2005) recomenda a utilização do método de estudo de caso, fundamentado teoricamente. Assim, segundo esse autor, ocorre a expansão e a generalização analítica, através da identificação de elos causais de um fenômeno dentro do seu contexto e numa comparação do presente com o futuro projetado.

0 estudo de caso utilizado no artigo, o fenômeno em questão, é a malha cicloviária de Curitiba em relação à rede de saúde, em seus dois momentos, a distribuição atual e a proposta do Plano de Estrutura Cicloviária de 2019 (Curitiba, 2019). Para essa análise, utilizou-se como base o procedimento metodológico sugerido por Vinicius Tischer, engenheiro ambiental e doutor em Ciência e Tecnologia Ambiental, no artigo intitulado "Validação de sistema de parâmetros técnicos de mobilidade urbana aplicados para sistema cicloviário" (Tischer, 2017). 0 autor discorre sobre a escassez de material bibliográfico sobre parâmetros de avaliação e planejamento de sistemas cicloviários no Brasil. Essa falta de material de pesquisa foi também notada nas buscas para a construção do referencial teórico deste artigo. 
Ao utilizar e adaptar o método de Tischer, portanto, confere-se validade ao trabalho de um pesquisador nacional.

O engenheiro propõe a composição de parâmetros matemáticos a partir da malha cicloviária, segundo práticas da Teoria dos Grafos de autores referenciados. Seu objetivo foi produzir um índice geral de qualidade de um sistema cicloviário, assim como existem os índices de avaliação em outras áreas, como o Índice de Desenvolvimento Humano (IDH). Para constituir esse índice, três parâmetros são necessários, conforme explica o autor.

Primeiramente, há o indicador de fragmentação da malha cicloviária, que expõe as deficiências em integração e continuidade da infraestrutura. Ele é dado pela Equação 1:

(1)

$$
f=\frac{1}{n_{t}}
$$

Onde $f$ é o fator de fragmentação; e $n_{t}$ é o número de trechos conectados e integrados da malha cicloviária. Quanto maior $f$, mais unificada e integrada é a malha de vias cicláveis.

O segundo parâmetro é a densidade do sistema cicloviário, que demonstra a proporção da disponibilidade de vias cicláveis em relação ao sistema viário. Ele é dado pela Equação 2:

(2)

$$
d=\frac{L_{c}}{L_{a c}}
$$

Onde $d$ é a densidade do sistema cicloviário; $L_{c}$ é a extensão total da malha cicloviária na cidade ou área avaliada; e $L_{a c}$ é a extensão das vias principais da cidade, isto é, as arteriais, coletoras e outras consideradas de trânsito rápido e de ligação. Essa escolha se justifica pela maior facilidade de se pedalar nas demais vias, de trânsito mais lento e local, nas quais a agressividade do condutor é menor e o ciclista se sente mais seguro (ibid.; Sousa e Penha-Sanches, 2019). Segundo a equação, quanto mais vias principais margeadas por estrutura cicloviária, maior seria a densidade.

Por último, há o chamado parâmetro gama $(\gamma)$, gerado conforme a Teoria dos Grafos. Os links $(L)$ - ou segmentos - seriam os trechos da malha e os nodes $(n)$ - ou vértices - seriam os entroncamentos e pontos finais das vias cicláveis. $O$ indicador gama é dado pela Equação 3:

(3)

$$
\gamma=\frac{L}{3(n-2)}
$$

Onde $\gamma$ é o índice de escolha de rotas; $L$ é o número de segmentos (trechos) da malha cicloviária; e $n$ é o número de vértices da maIha. Segundo a equação, $v$ teria um valor mais alto conforme os entroncamentos de trechos cicláveis fossem mais bem aproveitados, com maior possibilidade de rotas a partir de um mesmo nó. A partir dessa classificação abrangente e generalizada, é necessária a adaptação da metodologia para a avaliação da associação do sistema cicloviário com a saúde, no estudo de caso de Curitiba.

Como discorrido anteriormente, a prática do ciclismo está intimamente ligada à saúde física e mental do indivíduo, ainda mais no caso do ciclismo utilitário. Para avaliar a conexão da rede cicloviária de Curitiba com a saúde, foram explorados os acessos das Unidades Básicas de Saúde (UBS) ao sistema de vias cicláveis da cidade. Isso se justifica por duas razões:

1) As UBS são os locais onde a população busca serviços de atenção primária de saúde, como acolhimento, consultas médicas, de enfermagem e odontológicas, aplicação de vacinas, atendimento à saúde da mulher e do idoso, administração de medicamentos, e vários outros (Curitiba, 2020). O Ministério da Saúde 
destaca que $80 \%$ dos problemas de saúde dos cidadãos são resolvidos nas UBS, sendo elas as responsáveis pelos hábitos saudáveis de vida (Ministério da Saúde, 2013). Ou seja, os postos de saúde são procurados, na maior parte, em momentos que não exigem tratamento urgente e que não impedem necessariamente as pessoas de pedalar;

2) Um adequado sistema cicloviário depende da conexão entre diversos locais e estabelecimentos que atraem o deslocamento, os chamados Polos Geradores de Viagem (PGVs). Os edifícios da rede de saúde de uma cidade podem então ser colocados nessa classificação, conforme Cardoso e Campos (2014) descrevem. Segundo a PNMU (Brasil, 2012, art. 7)) a mobilidade deve "promover o acesso aos serviços básicos e equipamentos sociais", o que é o caso das UBS.

Ou seja, a ligação de postos de saúde a um sistema cicloviário indica a cobertura desse sistema sobre 0 atendimento de atividades básicas que as pessoas exercem no acesso à cidade. Assim, para quantificar a correlação das UBS de Curitiba com a malha cicloviária, criou-se mais um indicador para ser acrescentado aos anteriores de Tischer e completar o índice de avaliação da infraestrutura. É o indicador delta $(\delta)$, dado pela Equação 4:

(4)

$$
\delta=\frac{\sum_{i}^{n}\left(\frac{P A_{i}}{P_{i}}\right)}{n}
$$

Onde $\delta$ é o índice de atendimento da malha cicloviária à rede de saúde; $P$ é a população da área de abrangência da UBS i; PA é a população atendida nessa área; e $n$ é o número de UBS.
Tischer (2017) reúne os três parâmetros originais no chamado Índice de Mobilidade Cicloviária (IMCiclo). Na metodologia proposta neste trabalho, o quarto parâmetro agrega-se aos outros três, configurando o Índice de Mobilidade Cicloviária em relação à rede de Saúde (IMCS), dado pela Equação 5:

(5)

$$
I M C S=100 f d \gamma \delta
$$

Tanto o IMCiclo quanto o IMCS variam de 0 a 100, sendo capazes de indicar a qualidade geral de um sistema cicloviário, conforme uma classificação correspondente adaptada do trabalho de Tischer (ibid.):

$<1$ : pontual e inexistente;

Entre 1 e 3: insuficiente;

Entre 3 e 10: baixo;

Entre 10 e 20: regular;

Entre 20 e 30: adequado;

> 30: ótimo.

Com a obtenção do IMCS preestabelecida, a metodologia de coleta e sistematização dos dados relativos à rede cicloviária envolveu dois softwares: QGIS e Excel. No QGIS, foi feito o geoprocessamento de mapas a partir das informações sobre a malha viária, a malha cicloviária, as UBS de Curitiba e a densidade populacional. A rede cicloviária de Curitiba foi mapeada a partir dos dados disponíveis no Instituto de Pesquisa e Planejamento Urbano de Curitiba (IPPUC, 2019), aos quais foram adicionados os novos trechos, verificados in loco pelo autor. A população atendida numa área de abrangência de cada UBS foi obtida por meio do cruzamento de dados censitários (IBGE, 2010) com isócronas de 500 metros a partir das vias cicláveis conectadas à UBS em questão. Esse raio de distância é o recomendado como resolução de 
uma infraestrutura cicloviária conforme ITDP (2017). Já no Excel, os dados tabelados vindos do QGIS foram organizados para a realização dos cálculos e a confecção dos gráficos, adaptados em figuras e textos.

\section{O sistema cicloviário de Curitiba}

Curitiba, a capital do Paraná, com 1.948.626 habitantes em 2020 (IBGE, 2020), é conhecida pelo histórico sistema de transporte que inovou a relação entre mobilidade e planejamento. Os ônibus expressos, o sistema trinário de vias, a canaleta exclusiva de ônibus e a implantação dos setores estruturais de densificação do uso do solo em torno do transporte são os elementos que marcaram a cidade a partir da década de 1970 (Nichele, 2018).

Entretanto, a premissa de adensamento das quadras em volta da canaleta não impediu o fenômeno de periferização e metropolização. Com a valorização dos lotes próximos às estruturais com acesso ao transporte rápido, restou às camadas mais baixas a ocupação das bordas da cidade ou dos municípios vizinhos, tanto através de ocupações informais quanto pela produção de programas habitacionais (Lima et al., 2018).

Além disso, a falta de reformas estruturais no sistema da cidade, o aumento da tarifa e o contexto geral do País de incentivo à indústria automobilística e ao automóvel fizeram a taxa de motorização aumentar em Curitiba, onde ocorreu uma elevação de 46,5\% na quantidade geral de veículos entre 2007 e 2018 (Detran-PR, 2019). Em relação à quantidade de automóveis, os dados mais recentes mostram que, em 2018, o município tinha 50 automóveis para cada 100 habitantes, quase o dobro da média nacional daquele ano, de 26 carros para cada 100 habitantes (IBGE, 2020). Enquanto isso, o número de usuários do transporte público vem decaindo na capital paranaense. De 2015 (ano em que a integração metropolitana foi quebrada) a 2018 , houve queda de $18,5 \%$ na quantidade de passageiros transportados por ano (URBS, 2019).

Em relação ao modo cicloviário, o sistema nunca chegou a acompanhar qualquer inovação, como o transporte público de Curitiba. Tendo início com um passeio compartilhado de 3 quilômetros implantado em 1977, a malha cicloviária curitibana teve modestos aumentos em extensão (Curitiba, 2019), se comparados com a proporção da malha viária total. E essas implantações adicionais não significaram avanços em qualidade. Ao longo das décadas, vários trechos antigos foram descaracterizados e não receberam manutenção, e a rede de vias cicláveis curitibana ficou conhecida por interligar apenas os principais parques da cidade, caracterizando o modo de transporte apenas como prática de lazer esporádico (Goetten, 2017; Araújo, 2014).

A Figura 1 mostra algumas situações encontradas pelo autor, que é também um ciclista utilitário, na malha cicloviária da cidade. A primeira fotografia exibe uma sinalização encontrada no trecho que ladeia a linha do trem nos bairros Alto da XV, Hugo Lange e Cabral, oficialmente classificado como ciclovia, mas sinalizado e utilizado, na prática, como passeio compartilhado; já a segunda imagem é uma demonstração da infraestrutura incompleta, com a falta de rampa para a bicicleta (e o pedestre) acessar(em) a calçada compartilhada, colocando o usuário em risco na travessia do 
cruzamento. São apenas algumas evidências da incoerência e da precariedade da malha cicloviária de Curitiba. $\mathrm{O}$ objetivo deste trabalho não é desnudar minuciosamente esses detaIhes práticos, embora sejam relevantes para a qualidade do sistema, mas volver o olhar sobre as características gerais da rede e a relação com os equipamentos de saúde.

De 2011 a 2018, a extensão da malha cicloviária curitibana teve o aumento mais significativo, passando de 117 a 208 quilômetros, segundo informações do plano cicloviário (Curitiba, 2019), e, entre 2019 e 2020, mais alguns trechos foram construídos. Constatou-se que Curitiba tem 223,3 quilômetros de malha cicloviária (outubro de 2020), que são distribuídos em seis categorias (semelhantes às apresentadas anteriormente), além de alguns segmentos descaracterizados não considerados nessa conta: (1) ciclovias: espaços exclusivos, segregados fisicamente; (2) ciclofaixa no passeio: faixa preferencial à circulação da bicicleta junto à calçada; (3) ciclofaixa na via: faixa preferencial à circulação da bicicleta na pista de rolamento; (4) passeio compartilhado: espaço compartilhado com o pedestre na calçada; (5) via compartilhada: faixa compartiIhada com os veículos na pista de rolamento,

Figura 1 - Situações encontradas na malha cicloviária de Curitiba

Imagem 1

Sinalização de passeio compartilhado rua Padre Germano Mayer (Alto da XV)

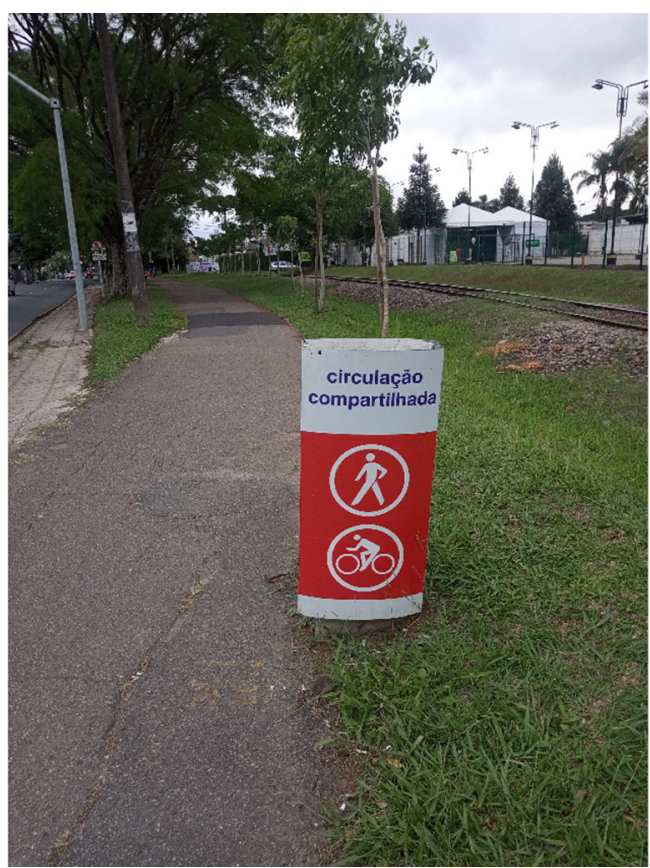

Fonte: autor (2020).
Imagem 2

Inexistência de rampa - rua Santo André versus avenida Pres. Affonso Camargo (Capão da Imbuia)

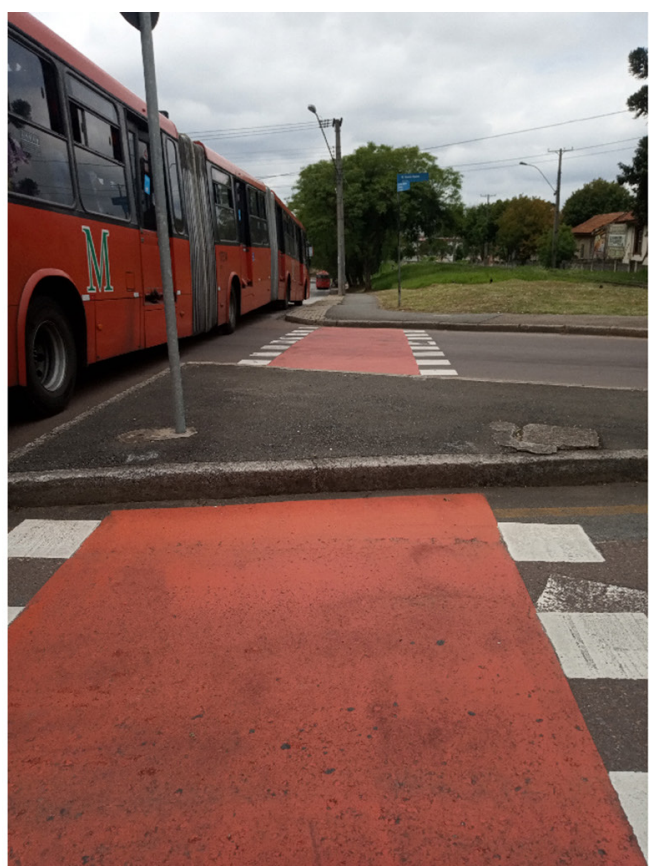


Figura 2 - Sistema cicloviário de Curitiba na atualidade (outubro de 2020)

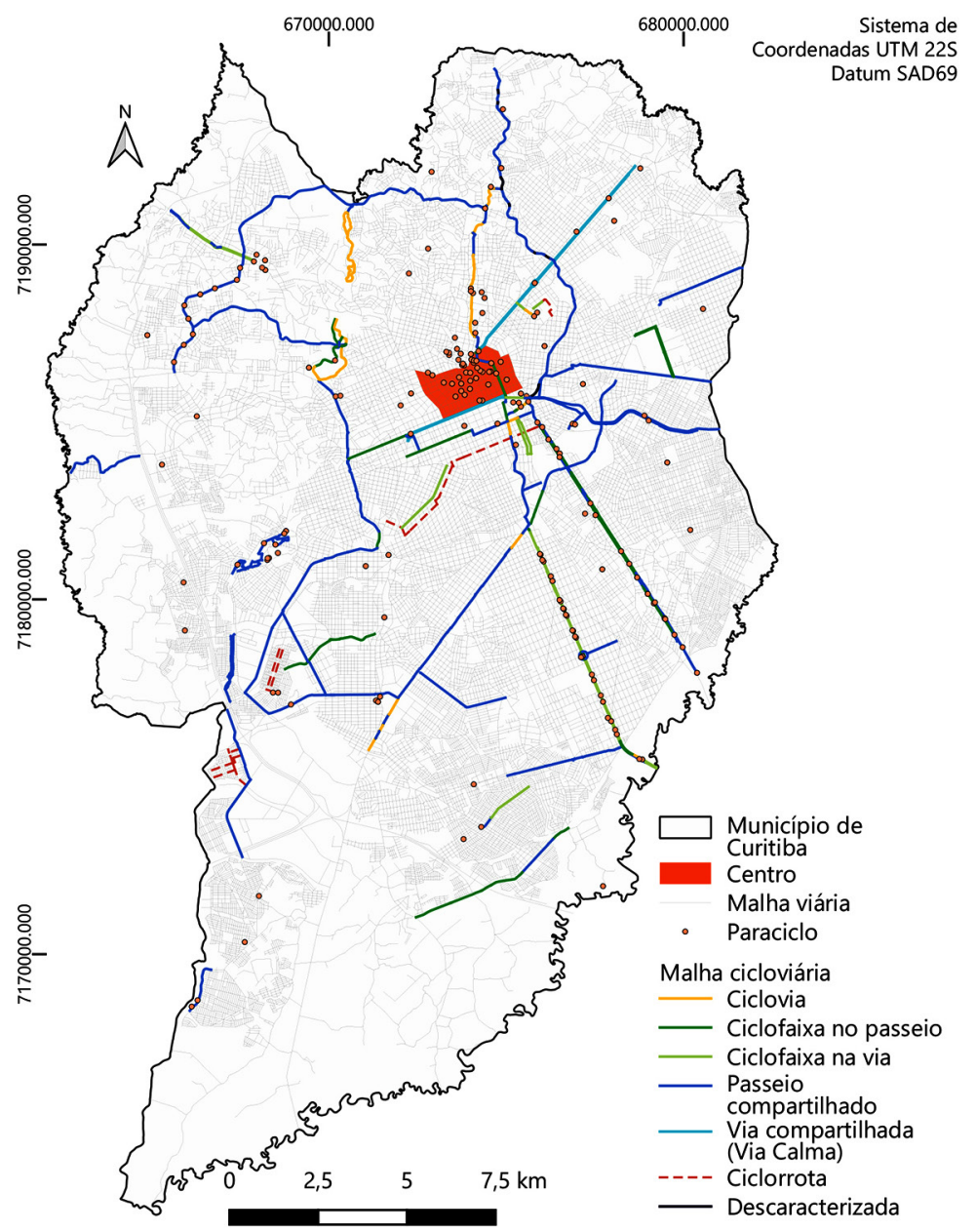

Fonte: elaboração própria, com base em IPPUC (2019).

com preferência do ciclista, sendo chamada de Via Calma; (6) ciclorrota: uso de via local para constituição de uma rota para o ciclista, com a divisão do espaço com o automóvel. A Figura 2 mostra a malha existente atualmente (outubro de 2020), segundo os seis tipos, apresenta a localização dos paraciclos e contextualiza a rede com a malha viária da cidade.
No cartograma, é possível verificar a fragmentação da malha cicloviária, com diversos trechos dispersos e desconectados e algumas poucas áreas mais bem servidas. $\mathrm{A}$ distribuição dos paraciclos não acompanha a rede, havendo maior número na área central da cidade. É notável, ainda, o predomínio de passeios compartilhados em comparação com 
os outros tipos. A Figura 3 apresenta a proporção dos tipos de vias cicláveis disponíveis atualmente. A maior parte $(63,6 \%)$ é composta de espaços compartilhados, enquanto a categoria de uso exclusivo dos ciclistas representa apenas $6,0 \%$ da malha total.

Em 2019, foi aprovado, por meio de decreto municipal, o Plano de Estrutura Cicloviária (Curitiba, 2019), desenvolvido peIo IPPUC. O plano fundamenta-se através do levantamento histórico da malha da cidade, mencionando o aumento da frota de carros e a necessidade de recuperar as ruas tanto para pedestres quanto para ciclistas. Em seguida, o documento realiza o inventário da malha cicloviária existente, catalogando informações do estado das ciclovias, da sinalização e dos equipamentos de apoio. O diagnóstico do plano reconhece a fragmentação do sistema de Curitiba, a falta de sinalização e identidade visual das vias e a baixa integração com o transporte por ônibus. 0 diagnóstico ainda recomenda a prática do ciclismo junto às estruturais dos expressos, desconsiderando, em parte, o uso da bicicleta nos bairros periféricos e a necessidade de expandir a rede para toda a cidade.

Como referências legais, o plano menciona o CTB (Brasil, 1997), a PNMU (Brasil, 2012) e o Plano Diretor do município, que foi revisado em 2015 e previu a melhoria da rede de ciclovias. Partindo para os critérios,

Figura 3 - Distribuição da proporção dos tipos de vias cicláveis em Curitiba - 2020

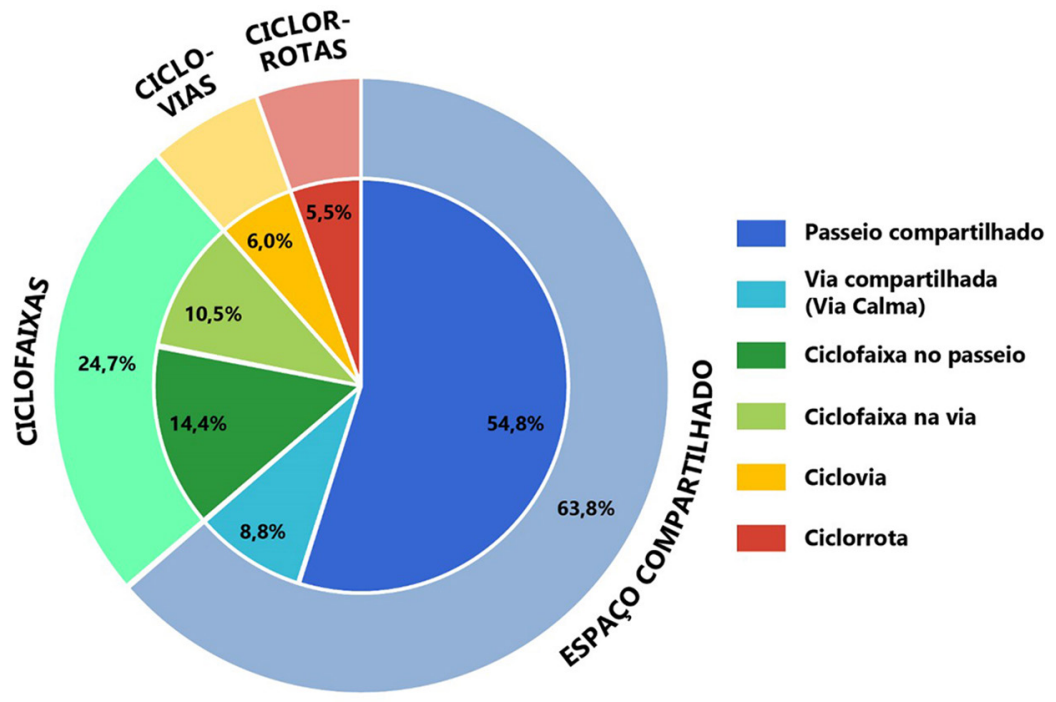

Fonte: elaboração própria, com base em Curitiba (2019). 
o documento descreve que vias mais largas e com trânsito mais intenso requerem pistas exclusivas e segregadas para ciclistas, enquanto, para vias lentas e mais estreitas, a solução seria o compartilhamento com outros modos (com o pedestre, nas calçadas, ou com os automóveis, na pista de rolamento). Como diretrizes, o Plano prevê o fechamento da maIha, a integração com os corredores de BRT e a associação com alguns grandes equipamentos. A Figura 4 mostra a esquematização da malha proposta no Plano a partir dessas diretrizes.

Figura 4 - Diretrizes do Plano de Estrutura Cicloviária de 2019

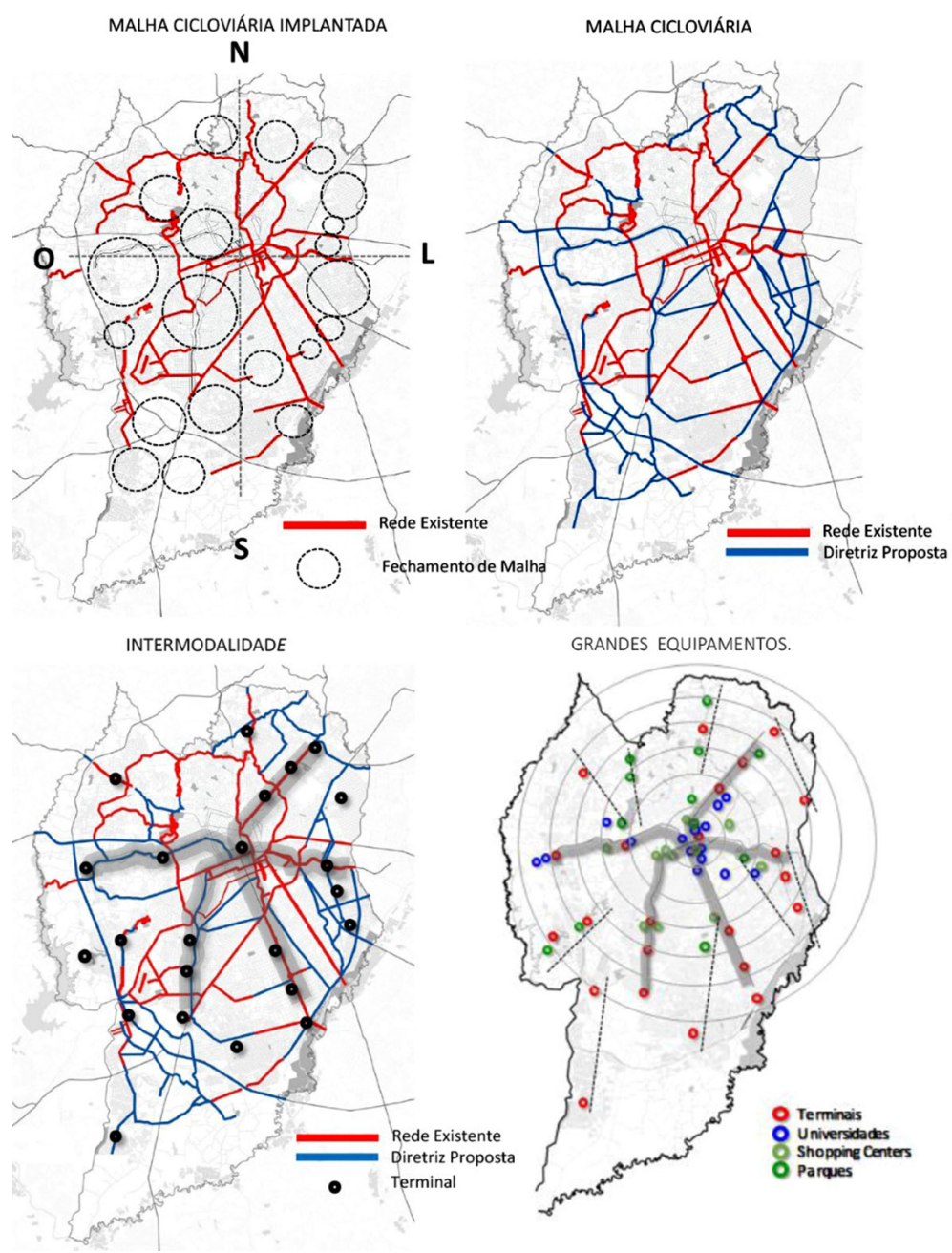

Fonte: Curitiba (2019). 
É interessante destacar algumas particularidades do Plano de Estrutura Cicloviária aprovado pela prefeitura de Curitiba. 0 próprio plano admite focar a rede em torno das estruturais e em alguns bairros revelados como palco intenso de ciclismo, por uma pesquisa origem/destino realizada em 2015. Porém, essa pesquisa foi feita com usuários que pedalavam no centro da cidade, privilegiando a movimentação em torno da área central e desconsiderando os bairros periféricos e os subcentros de comércio e emprego.

Outra questão é a ausência de participação popular na elaboração do plano. Houve, inclusive, uma nota de repúdio à prefeitura e ao IPPUC, assinada por professores da Universidade Federal do Paraná (UFPR), por engenheiros e arquitetos e, também, pela Associação dos Ciclistas do Alto Iguaçu (Cicloiguaçu) (Senge-PR et al., 2019). A nota menciona que as discussões com essas entidades conselheiras e com a comunidade ocorreram sem um método sistematizado e de maneira confusa, com as sugestões sendo descartadas e ignoradas no documento final. Para completar, o texto deixa explícitos os gastos vultosos que a prefeitura tem despendido com asfaltamento de ruas, conservando, portanto, a priorização do automóvel.

Além dessas críticas sobre o processo de concepção do plano, é relevante destacar comentários sobre a rede proposta, que seria concluída até 2025. Em relação às vias cicláveis previstas, não é especificado o tipo da construção, ou seja, não é possível saber quais serão as ciclovias, as ciclofaixas, os passeios compartilhados ou as ciclorrotas. Quanto aos locais de destino que nortearam os traçados propostos, o plano menciona que alguns grandes equipamentos ajudaram a orientar essa proposição. Segundo Geipot (2001) e ITDP (2017), deveriam ser os PGVs, identificados a partir de intensa e detalhada pesquisa. Porém, o plano colocou como pontos interessantes de destino apenas alguns terminais, universidades, shopping centers e parques, como se pode ver na Figura 4. É uma atitude que demonstra a desvalorização do ciclismo utilitário e que dá continuidade à interpretação da bicicleta como instrumento apenas de lazer, além de ser focalizado em classes favorecidas que se direcionam a universidades e locais de compra. Escolas municipais e estaduais, creches, postos de saúde, centros de comércio de bairro, praças de bairro, equipamentos de serviço e pontos de convergência de linhas de ônibus foram deixados de lado.

A rede proposta pelo plano, categorizada segundo prioridades de trechos a serem construídos, é apresentada na Figura 5, no contexto da malha viária e com a localização das UBS e sua conexão com o sistema, algo que será discutido adiante. No cartograma é possível verificar várias pontas soltas da malha, além de áreas densas sem acesso a vias cicláveis, problemas que o plano afirma resolver. Os trechos de prioridade estão, na maior parte, junto aos eixos estruturais de transporte, e as áreas periféricas têm atendimento previsto disperso e incongruente. 
Figura 5 - Sistema cicloviário de Curitiba

proposto pelo plano aprovado em 2019, junto às UBS

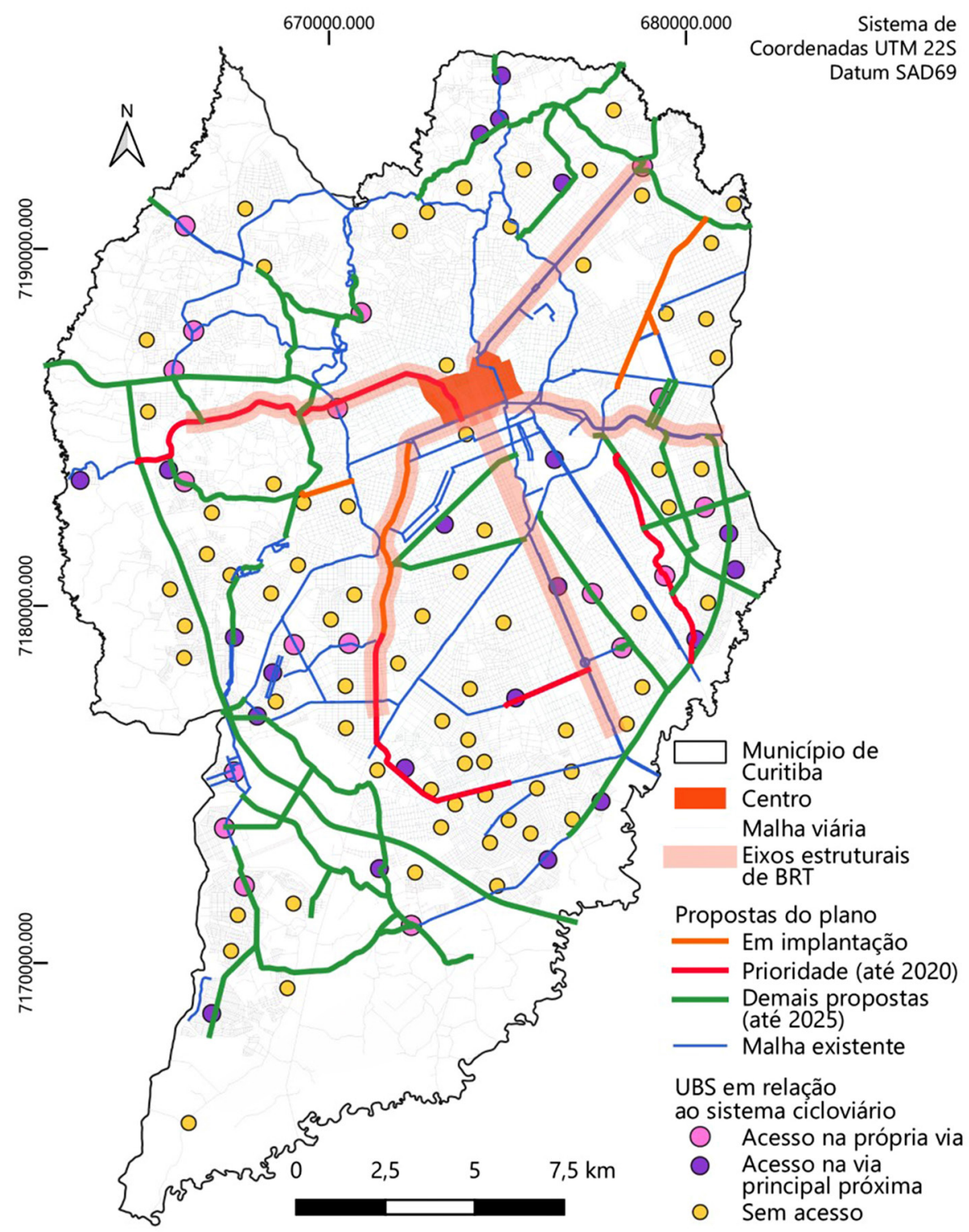

Fonte: elaboração própria, com base em Curitiba (2019). 


\section{Resultados e discussão}

Com essa avaliação geral do plano, parte-se para o cálculo do IMCS de Curitiba e para a análise da relação da rede de saúde com a malha cicloviária da cidade, conforme procedimento metodológico proposto. Existem atualmente 111 UBS no município, e cada unidade tem uma área delimitada de atuação, direcionando o usuário conforme o seu endereço de residência. A Figura 5 mostra a localização das UBS que terão acesso à malha cicloviária com a conclusão do plano, seja por acesso direto (no endereço do posto), seja por acesso indireto (na via principal mais próxima), e com aquelas sem conexão. Não há uma lógica nessa distribuição, já que tanto o sistema atual quanto o plano desconsideram as UBS como pontos a guiarem a malha. 0 que acontece é uma coincidência de a localização dos postos de saúde ser adjacente a uma via ciclável.

Os gráficos da Figura 6 mostram a proporção de postos de saúde ligados à malha cicloviária atual e à proposta no plano aprovado em 2019. Dos 111 totais, apenas 14\% dos postos (16 dos 111) são acessados por algum tipo de via ciclável; no projeto, essa porcentagem sobe para 34\% (38 dos 111), refletindo o aumento na extensão cicloviária próximo ao dobro. Em relação à disponibilidade de estacionamentos, apenas duas UBS possuem paraciclos atualmente, ambas não sendo acessadas tanto pela malha atual quanto pela projetada. O plano não menciona a instalação prevista de novos paraciclos na cidade.

Através do cálculo dos indicadores auxiliares, foi gerado o IMCS tanto para a malha atual quanto para a projetada no município, com os valores organizados no Quadro 1.
O IMCS atual é de 0,06, o que classifica o sistema cicloviário de Curitiba como pontual, inexistente e de viés recreacional. Se todos os trechos projetados fossem concluídos, a cidade teria um IMCS de 0,63, um aumento insignificante que não mudaria em nada a classificação do sistema. A rede cicloviária somente poderia ser avaliada como adequada, caso o IMCS fosse acima de 20, conforme classificação disposta anteriormente.

O cálculo do IMCS de Curitiba e a avaliação do cenário atual e do proposto para a maIha cicloviária do município permitem algumas interpretações críticas. O plano com certeza é um avanço, graças ao aumento quase que dobrado dos trechos de ciclovias, ciclofaixas e similares, mas singelo e irrelevante se compararmos com a necessidade e o tamanho da cidade. O IMCS calculado para o cenário projetado mostra como a cidade ainda estará longe de possuir uma rede cicloviária satisfatória.

O plano teve, ainda, uma construção controversa, menosprezando a participação popular e dispondo os critérios considerados de maneira tendenciosa, sem etapas metodológicas fundamentadas, como as descritas por Cardoso e Campos (2014). A própria implementação dos trechos projetados para o biênio 2019-2020 segue atrasada: até o final de 2020, 46,4 quilômetros deveriam estar construídos nessa primeira fase, chamada de prioritária. Em outubro de 2020, a apenas dois meses do fim do ano, dos 12 trechos que essa fase considerou, nenhum ficou pronto totalmente. Apenas 1,1 quilômetro foi construído, além de outros 2,9 quilômetros feitos e que não estavam na previsão do documento.

Em relação aos postos de saúde, estes não são atendidos majoritariamente e são desconsiderados nas proposições de avanço 
Figura 6 - Acesso das UBS ao sistema cicloviário de Curitiba

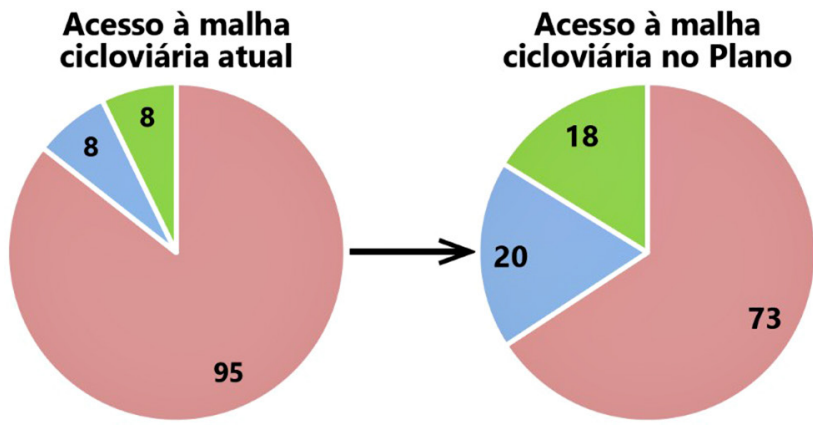

Acesso à malha cicloviária no Plano

Fonte: elaboração própria.

Quadro 1 - Cálculo do IMCS de Curitiba

Acesso direto

(na própria via)

Acesso indireto (na via principal mais próxima)

Sem acesso

\begin{tabular}{|c|r} 
Atual & Plano \\
\hline
\end{tabular}

\begin{tabular}{|c|c|c|}
\hline Cálculo & Atual & Plano \\
\hline$n_{t}$ & 13 & 7 \\
\hline$f=1 / n_{t}$ & 0,08 & 0,14 \\
\hline $\mathrm{L}_{\mathrm{c}}$ & $223.273,26$ & $416.337,42$ \\
\hline $\mathbf{L}_{\mathrm{ac}}$ & $1.007 .002,75$ & $1.007 .002,75$ \\
\hline$d=L_{c} / L_{a c}$ & 0,22 & 0,41 \\
\hline $\mathbf{L}$ & 123 & 241 \\
\hline n & 114 & 183 \\
\hline$\nu=L / 3(n-2)$ & 0,37 & 0,44 \\
\hline$\delta=\Sigma \mathrm{ni}(\mathrm{PAi} / \mathrm{Pi}) / \mathrm{n}$ & 0,09 & 0,24 \\
\hline IMCS $=100 \mathrm{fd} \gamma \delta$ & 0,06 & 0,63 \\
\hline
\end{tabular}

Fonte: elaboração própria.

da malha cicloviária da cidade. A negligência sobre as UBS, além de outros importantes PGVs, revela que o município não está, de fato, preocupado com o aperfeiçoamento da infraestrutura de sua rede cicloviária, muito menos com a priorização da bicicleta na distribuição modal. Tomar equipamentos de serviços e suas áreas de abrangência, como as UBS, poderia ser uma pedra fundamental na composição de diretrizes de vias cicláveis a serem implantadas, mas não é o que se propõe em Curitiba. 
Em suma, portanto, o Plano de Estrutura Cicloviária de Curitiba representa um aumento quantitativo da malha cicloviária, algo que, é claro, é bem-vindo, mas que depende da efetiva implantação. No entanto, o plano menospreza a importância do ciclismo na construção de mobilidade sustentável e integrada com o transporte público, ignorando as reivindicações e as necessidades reais de usuárias e usuários de bicicleta. Isso revela que Curitiba vai na contramão do estabelecimento de um sistema cicloviário de qualidade, que poderia contribuir para a mobilidade urbana sustentável e para a saúde da população do município, ainda mais no cenário pós-Covid-19.

\section{Considerações finais}

A bicicleta é o modo de transporte a ser considerado como prioridade para a mobilidade urbana acessível e sustentável. O momento atual, da pandemia no novo coronavírus, evidenciou a vantagem do ciclismo, não só pela possibilidade da manutenção do distanciamento social e da prática de exercícios físicos, mas principalmente pela representação de uma alternativa a ser combinada com o transporte público, diminuindo a pressão sobre ônibus, metrôs e trens e, também, retirando o automóvel das vias públicas.

Este artigo pretendeu reunir evidências teóricas sobre o tema e a importância do ciclismo utilitário e sua relação com hábitos saudáveis e com os equipamentos de saúde. Avaliar e entender as redes cicloviárias existentes nas cidades brasileiras é o primeiro passo para que os poderes públicos municipais possam propor melhorias efetivas. 0 IMCS, índice proposto no artigo para avaliar o sistema cicloviário em relação à rede de saúde, configura-se um meio de analisar a qualidade da malha cicloviária de uma cidade como um todo. No caso de Curitiba, o IMCS aponta um valor de apenas 0,06 (numa escala de 0 a 100), indicando o sistema cicloviário da capital paranaense como desagregado e ínfimo. O Plano de Estrutura Cicloviária aprovado por decreto municipal em 2019, que envolveu contradições sobre participação popular em sua elaboração, é tendencioso em criar uma falsa valorização da bicicleta. A aproximada duplicação projetada da malha, que eleva o IMCS a um banal valor de 0,63 , continua tratando o modo como exercício esporádico de lazer, sem real preocupação com a mobilidade sustentável e a multimodalidade. Ao não se atentar para a qualidade da sua infraestrutura ciclável, Curitiba está negligenciando a saúde de sua população, que segue submetida a um transporte público sucateado e ao aumento do trânsito de veículos particulares, com todos os consequentes problemas de poluição.

A partir das conclusões deste artigo, outras pesquisas futuras podem surgir. Os procedimentos metodológicos propostos para avaliação de um sistema cicloviário em relação às UBS, incluindo o cálculo do IMCS, são aptos à aplicação em estudos de outras cidades. A análise da conexão da malha cicloviária com a rede de saúde pode ser expandida para hospitais e postos de atendimento psicológico. Além disso, há oportunidade para outras problemáticas serem vinculadas aos índices de avaliação da ciclomobilidade, como as questões de gênero, raça, classe, custo da terra, localização de empregos e integração com o transporte público. Por fim, futuras propostas podem levar em conta os questionamentos e sugestões colocadas neste trabalho, a fim de um planejamento mais justo e abrangente de malhas cicloviárias. 


\section{https://orcid.org/0000-0002-0434-0892}

Universidade Federal do Paraná, Faculdade de Arquitetura e Urbanismo, Programa de Pós-Graduação em Planejamento Urbano. Curitiba, PR/Brasil.

he.nichele@gmail.com

\section{Referências}

ABILIO, C. C. C.; VASCONCELLOS, M. P. (2017). Eu Vou de Bike: a ocupação de bicicletas nos espaços públicos de São Paulo. Ponto Urbe, n. 20.

ALOI, A.; ALONSO, B.; BENAVENTE, J.; CORDERA, R.; ECHÁNIZ, E.; GONZÁLEZ, F.; LADISA, C.; LEZAMA-ROMANELLI, R.; LÓPEZ-PARRA, A.; MAZZEI, V.; PERRUCCI, L.; PRIETO-QUINTANA, D.; RODRÍGUEZ, A. e SAÑUDO, R. (2020). Efects of the COVID-19 Lockdown on Urban Mobility: Empirical Evidence from the City of Santander (Spain). Sustainability, v. 12, n. 3870.

ALVES, J. D.; CUNHA, E. L. (2017). O sistema cicloviário como alternativa para a mobilidade urbana: uma análise em piracicaba - São Paulo. Revista Científic@, v. 4, n. 1.

ARAÚJO, L. (2014). Curitiba terá mais $300 \mathrm{~km}$ de infraestrutura para bicicletas até 2016. Disponível em: http://vadebike.org/2014/05/plano-ciclovias-ciclofaixas-via-calma-curitiba/. Acesso em: 20 out 2020.

ARAÚJO-LIMA, C. de; TAPIE, G. (2018). "La mobilité en question. Les enseignements de Cincinnati (États-Unis) et Curitiba (Brésil)". In: GODIER, P.; OBLET, T.; TAPIE, G. (orgs.). L'éveil métropolitain: L'exemple de Bordeaux. Paris, Le Moniteur, pp. 167-202.

BATTISTON, M.; OLEKSZECHEN, N.; DEBATIN NETO, A. (2017). Barreiras e facilitadores no uso da bicicleta em deslocamentos diários: alternativas para a mobilidade urbana. Revista de Ciências Humanas, v. 51, n. 1, pp. 269-286.

BICICLETA BRASIL (2007). Caderno de Referência para elaboração de Plano de Mobilidade por Bicicleta nas Cidades. Secretaria Nacional de Transporte e da Mobilidade Urbana (do extinto Ministério das Cidades).

BORLOTI, E.; HAYDU, V. B.; KIENEN, N.; ZACARIN, M. R. (2020). Saúde mental e intervenções psicológicas durante a pandemia da Covid-19: um panorama. Revista Brasileira de Análise do Comportamento, v. 16, n. 1.

BRASIL (1997). Lei n. 9.503, de 23 de setembro de 1997. Institui o Código de Trânsito Brasileiro. Diário Oficial da União. Brasília.

(2012). Lei n. 12.587, de 3 de janeiro. Institui as diretrizes da Política Nacional de Mobilidade Urbana. Diário Oficial da União. Brasília.

CARDOSO, P. D.; CAMPOS, V. B. (2014). Metodologia para planejamento de um de sistema cicloviário. Transportes, v. 24, n. 4.

CARVALHO, C. H. (2016). Texto para discussão n. 2.194 - Mobilidade Sustentável: conceitos, tendências e reflexões. Brasília, Ipea. 
CARVALHO, C. O.; BRITO, F. L. (2016). Mobilidade urbana: conflitos e contradições do direito à cidade. Revista de Direito Econômico e Socioambiental, v. 7, n. 2, pp. 103-132.

CARVALHO, M. L.; FREITAS, C. M. (2012). Pedalando em busca de alternativas saudáveis e sustentáveis. Ciência \& Saúde Coletiva, v. 17, n. 6, pp. 1617-1628.

CURITIBA (2019). Decreto n. 1418, de 1ㅇ de novembro. Aprova o Plano de Estrutura Cicloviária e delega competências. Diário Oficial do Município de Curitiba, v. 211, Ano VIII. Curitiba.

(2020). Atenção Primária. Disponível em: http://www.saude.curitiba.pr.gov.br/atencaobasica/atecao-primaria.html. Acesso em: 20 out 2020.

DEL RIO, V. (1990). Introdução ao desenho urbano no processo de planejamento. São Paulo, Pini.

DEMO, P. (1995). Metodologia científica em Ciências Sociais. São Paulo, Atlas.

DETRAN-PR - Departamento de Trânsito do Paraná (2019). Estatísticas de trânsito. Disponível em: http://www.detran.pr.gov.br/Pagina/Estatisticas-de-transito. Acesso em: 26 out 2020.

DONG, E.; DU, H.; GARDNER, L. (2020). An interactive web-based dashboard to track Covid-19 in real time. The Lancet Infectious Diseases, v. 20, n. 5, pp. 533-534.

GEIPOT - Empresa Brasileira de Planejamento de Transportes (2001). Manual de Planejamento Cicloviário. Brasília, Geipot.

GIANNOTTI, M. (coord.) (2020). Boletim 10 - Mudanças no transporte coletivo de grandes cidades aumentaram o risco de contágio dos grupos mais vulneráveis. Rede de pesquisa solidária, v. 10. Disponível em: https://redepesquisasolidaria.org/boletins/boletim-10/mudancas-no-transportecoletivo-de-grandes-cidades-aumentaram-o-risco-de-contagio-dos-grupos-mais-vulneraveis/. Acesso em: 16 out 2020.

GOETTEN, C. (2017). Número de ciclistas cresce em Curitiba, mas infraestrutura segue precária. Brasil de Fato. Disponível em: https://www.brasildefato.com.br/2017/05/15/numero-de-ciclistascresce-em-curitiba-mas-infraestrutura-segue-precaria. Acesso em: 18 out 2020.

HAMMAMI, A.; HARRABI, B.; MOHR, M.; KRUSTRUP, P. (2020). Physical activity and coronavirus disease 2019 (Covid-19): specific recommendations for home-based physical training. Managing Sport and Leisure, v. 25, n. 1-6.

IBGE - Instituto Brasileiro de Geografia e Estatística (2010). Censo Demográfico 2010: Resultados do Universo. Disponível em: https://www.ibge.gov.br/estatisticas/downloads-estatisticas.html. Acesso em: 10 out 2020.

(2020). IBGE Cidades: Curitiba. Disponível em: https://cidades.ibge.gov.br/brasil/pr/curitiba/ panorama. Acesso em: 27 out 2020.

IPPUC - Instituto de Pesquisa e Planejamento Urbano de Curitiba (2019). Dados geográficos. Disponível em: https://ippuc.org.br/geodownloads/geo.htm. Acesso em: 20 out 2020.

ITDP-Instituto de Políticas de Transporte e Desenvolvimento (2017). Guia de Planejamento Cicloinclusivo. Rio de Janeiro, ITDP.

KATRAKAZAS, C.; MICHELARAKI, E.; SEKADAKIS, M.; YANNIS, G. (2020). A descriptive analysis of the effect of the COVID-19 pandemic on driving behavior and road safety. Transportation Research Interdisciplinary Perspectives, v. 7. 
LIMA, C. de; SILVA, M. N. da; TEXEIRA, A. G.; NICHELE, H. E. (2018). Incongruências entre moradia e mobilidade. Conjuntos de habitação popular e o sistema BRT em Curitiba. In: CONGRESSO OBSERVATÓRIO DAS METRÓPOLES 20 ANOS . Rio de Janeiro. Anais... Eixo 2 Gestão e Governança Urbana - Sessão 2.2 Mobilidade urbana. Rio de Janeiro, Observatório das Metrópoles, pp. 381-399.

MINISTÉRIO DA SAÚDE (2013). Entenda a diferença entre UBS e UPA. Disponível em: http://www.blog. saude.gov.br/geral/30302-entenda-a-diferenca-entre-ubs-e-upa. Acesso em: 20 out 2020.

MIRANDA, A. C.; VIEIRA, J. P. (2019). "A bicicleta é o veículo mais sustentável no ambiente urbano". In: ARAÚJO-LIMA, C. (org.). Mobilidade: abordagem multidisciplinar. Curitiba, Setor de Tecnologia, Universidade Federal do Paraná, pp. 96-134.

NAKAMORI, S.; BELOTTO, J. C.; JUNIOR, M. F.; OLIVEIRA, A. G. (2015). A contribuição da academia para mobilidade urbana sustentável por meio do programa de extensão universitária da UFPR Ciclovida. Revista Políticas Públicas \& Cidades, v. 3, n. 2, pp. 145-163.

NETTO, N. A.; RAMOS, H. R. (2017). Estudo da Mobilidade Urbana no Contexto Brasileiro. Revista de Gestão Ambiental e Sustentabilidade, v. 6, n. 2, pp. 59-72.

NICHELE, H. E. (2018). Plano de traçados de linhas estruturais no modal MagLev para o Núcleo Urbano Central da Região Metropolitana de Curitiba-PR: sistema de transporte e mobilidade sustentável. Monografia de graduação. Curitiba, Universidade Federal do Paraná.

OMS - Organização Mundial da Saúde (World Health Organization) (2020a). Coronavirus disease (Covid-19) advice for the public. Disponível em https://www.who.int/emergencies/diseases/ novel-coronavirus-2019/advice-for-public. Acesso em: 15 out 2020.

(2020b). WHO Director-General's opening remarks at the media briefing on Covid-19 - 11 March. Disponível em: https://www.who.int/director-general/speeches/detail/who-director-general-sopening-remarks-at-the-media-briefing-on-covid-19---11-march-2020. Acesso em: 10 out 2020.

PARK, S.; KIM, B.; LEE, J. (2020). Social distancing and outdoor physical activity during the Covid-19 outbreak in South Korea: Implications for physical distancing strategies. Asia Pacific Journal of Public Health, v. 32, n. 6-7, pp. 360-362.

PERES, A. C. (2020). Olha o breque!: movimento dos entregadores vem chamando atenção para a precaridade das relações de trabalho nas plataformas digitais. Radis: Comunicação e Saúde, v. 215, pp. 16-24.

PROGRAMA BRASILEIRO DE MOBILIDADE POR BICICLETA (BICICLETA BRASIL) (2007). Caderno de Referência para elaboração de: Plano de Mobilidade por Bicicleta nas Cidades. Brasília, Secretaria Nacional de Transporte e da Mobilidade Urbana.

RAMALHOSO, W. (2020). Pandemia escancara crise de moradia no Brasil, mas produzir casa adequada para todos é possível e urgente. Ecoa. Disponível em: https://www.uol.com.br/ecoa/reportagensespeciais/moradia-digna-e-prioridade-para-refazer-cidades-pos-covid/\#cover. Acesso em: 24 out 2020. 
SENGE-PR - Sindicato dos Engenheiros no Paraná; CICLOIGUAÇU - Associação dos Ciclistas do Alto Iguaçu; APUFPR - Associação de Professores da Universidade Federal do Paraná; SINDARQ-PR - Sindicato dos Arquitetos e Urbanistas do Paraná; CRESS - Conselho Regional de Serviço Social do Paraná; IAB/PR - Instituto de Arquitetos do Brasil PR (2019). Nota de repúdio à Prefeitura Municipal de Curitiba e ao IPPUC: Contra a falta de participação na elaboração do Plano Cicloviário e pela ausência de políticas públicas de mobilidade sustentável no governo municipal de Rafael Greca. Disponível em: http://www.senge-pr.org.br/noticia/entidades-criticam-faltade-transparencia-da-prefeitura-de-curitiba-no-plano-cicloviario/. Acesso em: 20 out 2020.

SOUSA, I.-C. N.; PENHA-SANCHES, S. D. (2019). Fatores influentes na escolha de rota dos ciclistas. EURE. Santiago, v. 45, n. 134, pp. 31-52.

TEIXEIRA, J. F.; LOPES, M. (2020). The link between bike sharing and subway use during the Covid-19 pandemic: the case-study of New York's Citi Bike. Transportation Research Interdisciplinary Perspectives, v. 6.

TISCHER, V. (2017). Validação de sistema de parâmetros técnicos de mobilidade urbana aplicados para sistema cicloviário. Urbe - Revista Brasileira de Gestão Urbana, v. 9, n. 3, pp. 587-604.

URBS - Urbanização de Curitiba S.A. (2019). Estatísticas do transporte. Disponível em: https://www. urbs.curitiba.pr.gov.br/transporte/estatisticas. Acesso em: 26 out 2020.

VALE, D. S. (2016). A cidade e a bicicleta: uma leitura analítica. Finisterra, v. 51, n. 103, pp. 45-66.

VASCONCELLOS, E. A. (2013). Mobilidade urbana: O que você precisa saber. São Paulo, Breve Companhia. YIN, R. K. (2005). Estudo de caso: planejamento e métodos. Porto Alegre, Bookman.

Texto recebido em 30/out/2020

Texto aprovado em 31/jan/2021 